\title{
Multidisciplinary Design of Electric Vehicles Based on Hierarchical Multi-objective Optimization
}

\author{
Kesavan Ramakrishnan,Massimiliano Gobbi, and Gianpiero Mastinu \\ Department of Mechanical Engineering \\ Politecnico di Milano,Milan, 20158, Italy \\ Pre-print \\ JOURNAL OF MECHANICAL DESIGN \\ Volume: 141 Issue: 9 \\ Article Number: 091404 \\ DOI: $10.1115 / 1.4043840$
}

\begin{abstract}
A method for the optimal design of complex systems is developed by effectively combining multi-objective optimization and analytical target cascading techniques. The complex systems with high dimensionality are partitioned into manageable subsystems that can be optimized using dedicated algorithms. The multiple objective functions in each subsystem are treated simultaneously and the interactions between subsystems are managed using linking and shared variables. The analytical target cascading algorithm ensures convergence of the optimal solution that meets the system level targets while complying with the subsystem level constraints. A design optimization of electric vehicles with in-wheel motors is formulated as a two level hierarchical scheme where the top level consists of a model representing the electric vehicle and the bottom level contains models of battery and suspension. The vehicle model includes an electric motor model and a power electronics model. Pareto-optimal solutions are derived holistically. The effectiveness of the proposed method for optimizing the complex systems is compared against the conventional all-in-one optimization approach.
\end{abstract}

\section{Introduction}

A holistic approach for the design optimization vehicles considering all the relevant customer requirements on range, driving performance, weight and cost can assist designers in the early concept development. Using multi-level optimization technique, such a complex problem can be decomposed into multiple manageable subsystems and the interactions between them are managed using coordination strategies such as analytical target cascading (ATC), collaborative optimization (CO), network target coordination (NTC), and bi-level integrated system synthesis (BLISS). This paper employs ATC algorithm to optimize IWM electric vehicles. The generic framework of the ATC method was structured by Kim et al. based on the activities performed in the product development organization of automotive industry in [1]. The convergence of the method was studied in [2] and proved that an optimum solution can be found by recursively solving the hierarchical problems. Researchers have implemented the hierarchical approach in different interesting applications such as engine calibration [3], combined product and process design [4], and marketing linked product development process [5]. Whenever there are multiple objective functions in each subsystem, the designer can employ Multi-objective optimization (MOO) techniques to obtain the Pareto-optimal solutions.

Several methods exist in the literature to solve the AiO multi-objective optimization problems. Scalarization methods transform the MOO problem into a single objective problem either by weighting the normalized objective functions [6] or by optimizing one of the objective functions while using the others as constraints [7]. The Pareto methods handle the objective functions simultaneously. Pareto filtering method numerically filters the non-dominated solutions from the complete feasible solution space [8]. Weighted sum and constraint Pareto methods are similar to the scalarization methods, yet the weights and constraint values are varied, respectively, to get the complete Pareto optimal set. Multi-objective evolutionary algorithms rank the population by nondomination and work iteratively to obtain the Pareto front [9]. The authors in [10,11] have optimised the electric motor geometry based on the conflicting design objectives at the vehicle level using Pareto filtering. Bingzhan et al. applied multi-objective evolutionary algorithms for component sizing and the control strategy optimization of hybrid electric powertrain in [12]. However, the model complexity that can be handled by the AiO multi-objective optimization is limited. By combing the MOO techniques with ATC algorithm, the optimum solutions for complex systems can be derived effectively. 
In order to analytically model the in-wheel motors, an appropriate method should be selected from the possible electromagnetic models in the literature by analyzing their performance differences. The authors in [13] compared the electric motor models such as Carter factor, relative permeance model [14], complex relative permeance model [15], Schwarz-Christoffel Toolbox based semi-analytical conformal mapping (SC) [16], mode-matching (MM) [17], and harmonic model (HM) [18]. Based on the results discussed, the complex relative permeance model [19] is selected as it gives reasonable accuracy with minimum computational effort.

As the increased unsprung mass of the IWM electric vehicles is one of the key concerns that the designers should address in the early design optimization, the battery and suspension components are optimized together with the electric motor. Vehicle discomfort, road holding, and working space are considered as the objective functions as in [20,21]. Suspension spring stiffness and damping ratio are taken as the design variables. A battery model is used to arrange the cells in a balanced scheme to achieve uniform utilization. The number of cells in series and parallel are calculated from the voltage and current requirements of the motor. It is important to ensure that the energy requirement of the vehicle over targeted range is satisfied by the battery pack.

The paper is organized as follows: Section 2 presents the generic flowchart and mathematical formulation of ATC approach. In Section 3, the electric vehicle optimization problem is analyzed in detail and the objective functions are derived.Section 4 elaborates the optimization algorithms used for each subsystem. The coordination theory along with the Pareto-optimal results are discussed in Section 5. A comparative analysis is presented in Section 6 between the proposed method and the conventional AiO approach.

\section{ATC formulation}

A generic flowchart of analytical target cascading approach is shown in Fig.1. The optimised results from system model are cascaded to the subsystems as targets and the responses from subsystem models are given back for further corrections. This feedback based interactions are handled using linking variables. The design variables that are used in multiple subsystem models are treated as shared design variables.

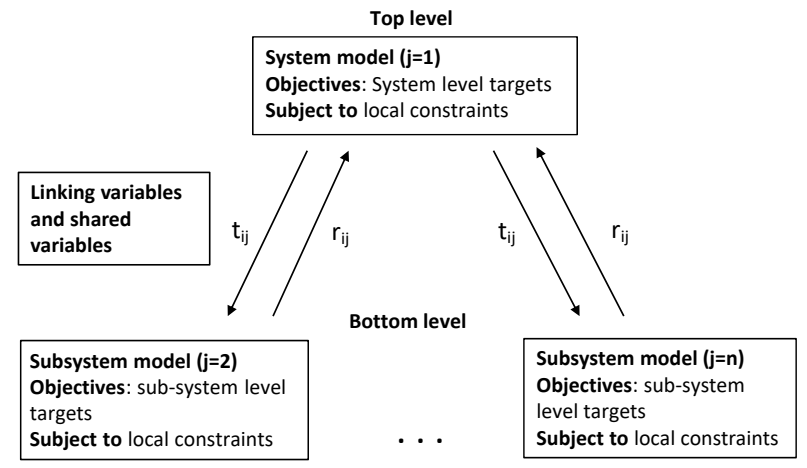

Fig. 1: General hierarchical partitioning structure.

The mathematical formulation ATC subproblem for the $i^{\text {th }}$ level and the $j^{\text {th }}$ element is given as:

$$
\begin{aligned}
\min _{\bar{x}_{i j}=\left\{x_{i j}, t_{i j}, r_{i j}\right\}} & f_{i j}\left(\bar{x}_{i j}\right)+\phi_{i j}\left(c_{i j}, v_{i j}, w_{i j}\right) \\
\text { subject to } & h_{i j}\left(\bar{x}_{i j}\right)=0 \\
& g_{i j}\left(\bar{x}_{i j}\right) \leq 0 \\
\text { where, } & \phi_{i j}=v_{i j}^{T} c_{i j}+\left\|w_{i j} \circ c_{i j}\right\|_{2}^{2} \\
& c_{i j}=t_{i j}-r_{(i+1) j}
\end{aligned}
$$

where $f_{i j}$ is the objective functions vector of each sub-system, $t_{i j}$ is the target linking variables vector from $j^{\text {th }}$ element of $i^{t h}$ level, $r_{(i+1) j}$ is the response linking variables vector from $j^{t h}$ element of $(i+1)^{t h}$ level, $\phi_{i j}$ is the consistency constraints vector which relaxes the equality constraints $\left(c_{i j}=0\right)$ between targets and responses using augmented-lagrangian (AL) function [22], $h_{i j}$ and $g_{i j}$ are the equality and inequality constraints vectors respectively, and $x_{i j}$ is the local design variables 
Table 1: Optimization problem for the complete vehicle

\begin{tabular}{lll}
\hline Objective functions & & \\
Energy consumption $(\mathrm{kWh})$ & $E_{c}$ & $(3)$ \\
Gradeability & $G L$ & $(37)$ \\
Discomfort $\left(\mathrm{m} / \mathrm{s}^{2}\right)$ & $\sigma_{\ddot{x_{2}}}$ & $(33)$ \\
Road holding $(\mathrm{N})$ & $\sigma_{F_{z}}$ & $(32)$ \\
Working space $(\mathrm{m})$ & $\sigma_{x_{2}-x_{1}}$ & \\
Design variables & $k_{a}$ \\
Axial scaling ratio & $k_{r}$ \\
Radial scaling ratio & $V_{r}$ \\
Rated voltage $(\mathrm{V})$ & $I_{m a x}$ \\
Maximum current of motor $(\mathrm{A})$ & $P_{i n}$ \\
Motor input power $(\mathrm{kW})$ & $N_{E M}$ \\
Number of motors & $N_{s c}$ \\
Number battery cells in series & $N_{p c}$ \\
Number battery cells in parallel & $k_{2}$ \\
Spring stiffness $(\mathrm{N} / \mathrm{m})$ & $r_{2}$ \\
Damping ratio $(\mathrm{Ns} / \mathrm{m})$ & $k_{3}$ \\
Relaxation spring stiffness $(\mathrm{N} / \mathrm{m})$ & $m_{e}$ \\
Inerter equivalent mass $(\mathrm{kg})$ & \\
Constraints & $E_{c} \leq E_{b a t t}$ \\
$E_{c} \leq$ Battery capacity $(\mathrm{kWh})$ & $P_{i n} \leq \frac{P_{b a t t}}{N_{E M}}$ \\
$P_{i n} \leq$ Battery output power $(\mathrm{kW})$ & $\sigma_{\ddot{x}} \leq L_{1}$ \\
Minimum required $\sigma_{\ddot{x}}$ & $\sigma_{x_{2}-x_{1}} \leq L_{2}$ \\
Minimum required $\sigma_{x_{2}-x_{1}}$ & $\sigma_{F_{z}} \leq L_{3}$ \\
Minimum required $\sigma_{F_{z}}$ & \\
\hline
\end{tabular}

vector. The symbol $\circ$ is used to denote term-by-term multiplication of vectors. The Lagrangian multiplier $(v)$ and penalty weight $(w)$ are updated linearly in the successive ATC iterations as in (2).

$$
\begin{aligned}
v^{y+1} & =v^{y}+2 w^{y} \circ w^{y} \circ c^{y} \\
w^{y+1} & =\beta w^{y}
\end{aligned}
$$

where y represents the iteration number. The factor $\beta$ should be $2<\beta<3$ for fast convergence [22]. The convergence criteria is set at the top-level as $\left\|c^{y}\right\|<\varepsilon_{1}$ and $\left\|c^{y}-c^{y-1}\right\|<\varepsilon_{2}$. The values of $\varepsilon_{1}$ and $\varepsilon_{2}$ are predefined by the designers.

\section{Optimization of in-wheel motor electric vehicles}

The considered in-wheel motor electric vehicles have two outer rotor motors mounted in the rear wheels and a Li-ion battery back. The conventional spring-damper suspension is used for the study. Table 1 gives the list of all the objective functions, design variables, and constraints of the optimization problem.

The proposed method manages the complexity of the optimization problem by partitioning it into multiple subsystems and arranging them in a hierarchical order. The design targets of the vehicle are either handled at the system level and cascaded down to the subsystems or passed directly to the lower levels. For example, in the two-level electric vehicle model, the targets on vehicle performance are handled at the top level, whereas the ride performance targets $\left(L_{1-3}\right)$ are given to the suspension model at the bottom level as constraints.

\subsection{System model: In-wheel motor electric vehicle}

At the system level, the objective functions are the energy consumption of the vehicle in a given range target as per $\operatorname{NEDC}\left(E_{c}\right)$ and driving performance. Gradeability limit $(G L)$, which is directly related to acceleration and fun-to-drive, is 
considered to quantify the driving performance. The design variables are axial and radial scaling ratios $\left(k_{a}\right.$ and $\left.k_{r}\right)$ of the electric motor as in Fig. 2, the rated voltage $\left(V_{r}\right)$, and the total number of battery cells $\left(N_{b c}\right)$. The optimum value of $N_{b c}$ is cascaded to the battery model as a target. Similarly, the $m_{1}$ and $m_{2}$ are given to the suspension model. The motor input power requirement $P_{i n}$ is treated as a shared variable. The constraints are defined on the energy content of the battery and the maximum allowable motor power $\left(P_{i n}\right)$.
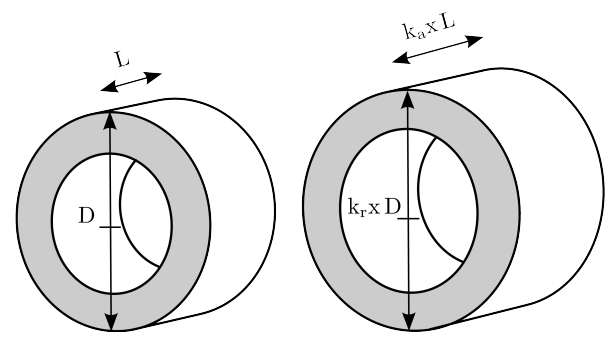

Fig. 2: Radial and axial scaling of motor.

The objective functions, design variables, and constraints of the top-level system model are listed in Table 2. The considered vehicle parameters and requirements are given in Table 3.

Table 2: Optimization problem for the system model

\begin{tabular}{cc}
\hline Objective functions & $E_{c}, G L$ \\
Design variables & $k_{a}, k_{r}, N_{b c}, V_{r}$ \\
Linking variables & $N_{b c}, m_{2}, m_{1}$ \\
Shared variable & $P_{\text {in }}$ \\
Constraints & $E_{c} \leq E_{\text {batt }} ; N_{E M} P_{\text {in }} \leq P_{\text {batt }}$ \\
\hline
\end{tabular}

Table 3: Vehicle parameters and requirements used in the optimization

\begin{tabular}{cc}
\hline Vehicle mass $\left(\mathrm{m}_{\mathrm{v}}\right), \mathrm{kg}$ & $\begin{array}{c}\mathrm{m}_{\text {body }}+\mathrm{m}_{\text {batt }}+ \\
\mathrm{m}_{\text {motor }} N_{E M}\end{array}$ \\
Vehicle body mass $\left(\mathrm{m}_{\text {body }}\right), \mathrm{kg}$ & 800 \\
Motor mass $\left(\mathrm{m}_{\text {motor }}\right), \mathrm{kg}$ & $\begin{array}{c}\text { Depends on } \mathrm{k}_{\mathrm{a}}, \mathrm{k}_{\mathrm{r}} \\
\text { Depends on } \mathrm{N}_{\mathrm{bc}}\end{array}$ \\
Battery mass $\left(\mathrm{m}_{\text {batt }}\right), \mathrm{kg}$ & 0.787 \\
Battery cell mass $\left(\mathrm{m}_{\text {cell }}\right), \mathrm{kg}$ & 2 \\
Frontal Area $(\mathrm{A}), \mathrm{m}^{2}$ & 0.25 \\
Co-efficient of drag $\left(\mathrm{C}_{\mathrm{d}}\right)$ & 2 \\
Number of motors $\left(N_{E M}\right)$ & 0.01 \\
Rolling resistance coefficient $\left(\mathrm{C}_{\mathrm{r}}\right)$ & 0.32 \\
Wheel radius $\left(\mathrm{R}_{\mathrm{w}}\right), \mathrm{m}$ & 250 \\
Required range, $\mathrm{km}$ & 0.8 \\
$L_{1}, m / s^{2}$ & $20 \mathrm{e}-3$ \\
$L_{2}, \mathrm{~m}$ & 400 \\
$L_{3}, \mathrm{~N}$ &
\end{tabular}




\subsubsection{Energy consumption $\left(E_{c}\right)$ calculation}

The total energy consumption of the vehicle $E_{c}$ is the summation of energy consumption in the electric motors $\left(E_{E M}\right)$ and the power electronics $\left(E_{P E}\right)$ within the targeted range $\left(R_{t}\right)$.

$$
E_{c}=\frac{R_{t}}{D_{D C}} \frac{N_{E M}\left(E_{E M}+E_{P E}\right)}{3600 \times 1000}
$$

where $D_{D C}$ is the distance travelled in a single driving cycle. The electric motor input power, which is the sum of tractive power $\left(P_{D C}\right)$ and the motor losses such as copper losses $\left(P_{a}\right)$, core losses $\left(P_{c}\right)$, magnet losses $\left(P_{P M}\right)$, and mechanical losses $\left(P_{\text {mech }}\right)$, is integrated over the driving cycle to get $E_{E M}$.

$$
E_{E M}=\int_{0}^{t_{D C}}\left(P_{D C}+P_{c}+P_{m e c h}+P_{P M}+P_{a}\right) d t
$$

where $P_{D C}$ is defined as tractive torque at the wheel $\left(T_{D C}\right)$ times the angular speed $(\Omega)$. The tractive torque in a driving cycle is calculated by multiplying the sum of aerodynamic resistance, gradient force, rolling resistance and inertial force with the wheel radius $\left(R_{w}\right)$ as in (5) [23].

$$
T_{D C}=\left(m_{v} a+m_{v} g \sin \alpha+m_{v} g C_{r} \cos \alpha+\frac{1}{2} C_{d} \rho_{0} A v^{2}\right) R_{w}
$$

In order to size the electric motor in the optimization, an analytical electromagnetic model based on conforming mapping is employed [24]. The model derives the air-gap magnetic field solution from motor geometry and estimates the losses at each time instant in the driving cycle. Though it is possible to optimize the motor parameters, such as number of poles, number of slots, and slot opening, using the analytical model, a simplified approach by scaling a reference motor geometry is adopted as in [25]. The motor dimensions are scaled in the radial and axial directions and used in the field distribution calculation. The slotted air gap $\left(B_{s}\right)$ field is derived by multiplying the complex conjugate of the complex relative permeance $\left(\lambda^{*}\right)$ and the canonical slotless air-gap flux density $\left(B_{k}\right)[19]$.

$$
B_{s r}+j B_{s \theta}=\left(B_{k r}+j B_{k \theta}\right)\left(\lambda_{r}+j \lambda_{\theta}\right)^{*}
$$

The flux linkage of phase winding $\left(\Psi_{P M-p h}\right)$ is obtained by integrating the radial flux density across one coil pitch and multiplying it with the number of coils in series $\left(N_{s}\right)$.

$$
\Psi_{P M-p h}=N_{s} l_{a} R \int_{-\frac{\gamma_{c}}{2}}^{+\frac{\gamma_{c}}{2}} B_{s r}(R, \theta, t) d \theta
$$

Flux linkage in the $\mathrm{d}$ axis $\left(\Psi_{d}\right)$ is derived by performing Park transformation of the phase winding flux linkages due to permanent magnets $\left(\Psi_{P M-d}\right)$ and adding the contribution of the flux linkage from the d-axis current.

$$
\Psi_{d}=\Psi_{P M-d}+L_{d} I_{d}
$$

In SPM machines, the core loss is dominated by the permanent magnet flux variations in stator, so the effect of armature flux variation and the losses in rotor are neglected. A generic expression for the core losses considering the effect of flux density harmonics can be written in the form (9) [26].

$$
P_{c}=\left[k_{h} f B_{m}^{a_{h}+b_{h} B_{m}}+k_{e} f^{2} \sum_{n} n^{2} B_{n}^{2}\right] \rho_{c} V_{c} \quad[W]
$$

where $k_{h}$ is the hysteresis loss coefficient, $k_{e}$ is the eddy current loss coefficient, $f$ is the electrical frequency, $B_{m}$ is the peak value of flux density waveform and $B_{n}$ represents the Fourier coefficients of the flux density waveform. The 
coefficients $a_{h}$ and $b_{h}$ are determined by curve fitting the steel lamination data provided by manufacturers [26]. The flux density in the tooth and yoke regions are calculated by integrating the radial component of air-gap field solution across slot pitch as explained in [26].

The mechanical loss is modeled as a sum of friction loss in the bearing and windage loss [27], which are functions of rotor mass $\left(m_{r}\right)$, stack length $\left(l_{a}\right)$, rotor outer diameter $\left(D_{r 0}\right)$, speed $\left(n_{r}\right)$, and an empirical coefficient $\left(k_{f b}\right)$.

$$
P_{m e c h}=k_{f b} m_{r} n_{r} 10^{-3}+2 D_{r 0}^{3} l_{a} n_{r}^{3} 10^{-6}
$$

Eddy current loss in the magnet induced by variations in armature field is calculated based on the methodology in [26]. The permanent magnet loss $\left(P_{p m}\right)$ are defined as a function of $d q$ axis currents.

The copper loss model considers only the DC losses in the armatures of all three phases and formulated as (11).

$$
P_{a}=3 I_{s}^{2} R_{a}
$$

where $R_{a}$ is the armature resistance and $I_{s}=\left(=\sqrt{I_{d}^{2}+I_{q}^{2}}\right)$ is the stator current that satisfies the torque demand at the wheel and motor losses. As per the maximum torque per ampere (MTPA) control strategy, the Id current is forced to zero in the constant torque region of the motor and defined as (12) in the field weakening region [28].

$$
I_{d}=\frac{\psi_{d}^{2}+L_{s}^{2} I_{\max }^{2}}{2 L_{s} \psi_{d}}\left[\left(\frac{\omega_{s}^{A}}{\omega}\right)-1\right]
$$

where $I_{\max }$ is the maximum stator current and $\omega$ is the operating speed. The rated speed of the motor $\omega_{s}^{A}$ is derived from the rated voltage of the motor $V_{r}$.

$$
w_{s}^{A}=\frac{V_{r}}{\sqrt{\left(L_{s} I_{q}\right)^{2}+\left(\psi_{p m}+L_{s} I_{d}\right)^{2}}}
$$

In order to calculate the Iq current, the motor output torque estimation model is modified as an optimization problem in (14) and the MATLAB function fmincon is used with the constraints on maximum voltage $\left(V_{\max }\right)$ and current $\left(I_{\max }\right)$.

$$
F=\left|T_{D C}-\left(T_{e m}\left(I_{d}, I_{q}\right)-\frac{P_{c}+P_{P M}\left(I_{d}, I_{q}\right)+P_{m e c h}}{\Omega}\right)\right|
$$

where the electromagnetic torque $\left(T_{e m}\right)$ of the motor is defined as [28]

$$
T_{e m}=\frac{3}{2} p \psi_{d} I_{q}
$$

For the Power electronics model, the most widely used space vector pulse width modulation (SVPWM) scheme is adopted due its effective dc bus utilization and reduced harmonics [29]. The circuit model of a typical three-phase voltage source inverter (VSI) is shown in Fig. 3. The three legs (A,B, and C) have six power switches $\left(S_{1}\right.$ to $\left.S_{6}\right)$ which are composed of insulated-gate bipolar transistors (IGBT) and diodes.

The relationship between the switching variable vector $[m, n, o]^{t}$ and the phase voltage vector $\left[\vec{V}_{a n} \vec{V}_{b n} \vec{V}_{c n}\right]^{t}$ is given in (16) [29].

$$
\left[\begin{array}{l}
\vec{V}_{a n} \\
\vec{V}_{b n} \\
\vec{V}_{c n}
\end{array}\right]=\frac{V_{b a t t}}{3}\left[\begin{array}{rrr}
2 & -1 & -1 \\
-1 & 2 & -1 \\
-1 & -1 & 2
\end{array}\right]\left[\begin{array}{l}
m \\
n \\
o
\end{array}\right]
$$

The switching variable vector has binary digits, e.g. 101, which indicate the switch state of inverter legs. The digits 1 and 0 imply the ON state of the upper and lower switches, respectively. The two switches of the same leg are not switched ON or 


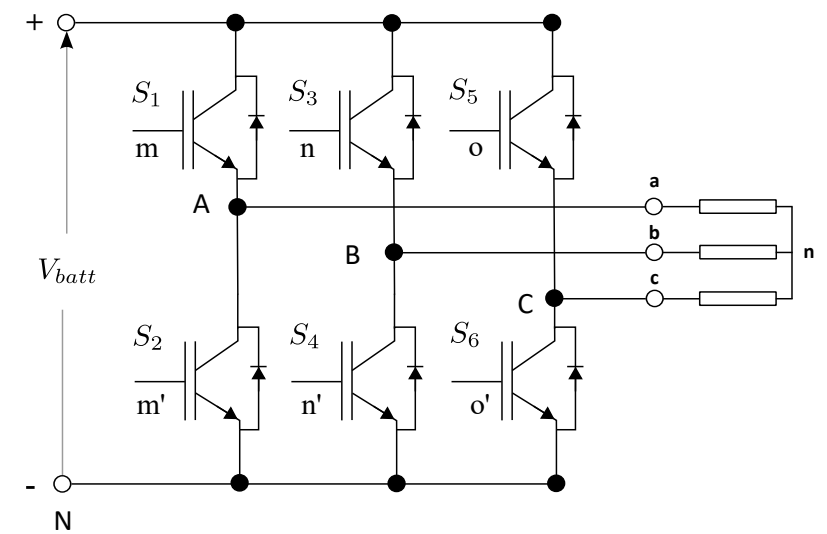

Fig. 3: Circuit model of a typical three-phase voltage source inverter.

OFF simultaneously to avoid short-circuiting. The most significant bit of the switching variable vector represent the leg A, the least significant bit is related to leg $\mathrm{C}$ and the middle is for leg $\mathrm{B}$.

There are eight possible combinations $\left(\vec{V}_{1-8}\right)$ of switching patterns for the three upper switches. The phase vector voltage corresponding to each switching pattern is defined in Table. 4.

Table 4: Phase voltage value for different switching states.

\begin{tabular}{cccccc}
\hline State & $\begin{array}{c}\text { Switching } \\
\text { vector }\end{array}$ & $\begin{array}{c}\text { Switches } \\
\text { ON }\end{array}$ & $\vec{V}_{\text {an }}$ & $\vec{V}_{\text {bn }}$ & $\vec{V}_{c n}$ \\
\hline 1 & 100 & $1,4,6$ & $\frac{2}{3} V_{\text {batt }}$ & $-\frac{1}{3} V_{\text {batt }}$ & $-\frac{1}{3} V_{\text {batt }}$ \\
2 & 110 & $1,3,6$ & $\frac{1}{3} V_{\text {batt }}$ & $\frac{1}{3} V_{\text {batt }}$ & $-\frac{2}{3} V_{\text {batt }}$ \\
3 & 010 & $2,3,6$ & $-\frac{1}{3} V_{\text {batt }}$ & $\frac{2}{3} V_{\text {batt }}$ & $-\frac{1}{3} V_{\text {batt }}$ \\
4 & 011 & $2,3,5$ & $-\frac{2}{3} V_{\text {batt }}$ & $\frac{1}{3} V_{\text {batt }}$ & $\frac{1}{3} V_{\text {batt }}$ \\
5 & 001 & $2,4,5$ & $-\frac{1}{3} V_{\text {batt }}$ & $-\frac{1}{3} V_{\text {batt }}$ & $\frac{2}{3} V_{\text {batt }}$ \\
6 & 101 & $1,4,5$ & $\frac{1}{3} V_{\text {batt }}$ & $-\frac{2}{3} V_{\text {batt }}$ & $\frac{1}{3} V_{\text {batt }}$ \\
7 & 111 & $1,3.5$ & 0 & 0 & 0 \\
8 & 000 & $2,4,6$ & 0 & 0 & 0 \\
\hline
\end{tabular}

It is possible to transform the three-phase voltage vectors to equivalent two-phase vector, because one of the phase voltages is redundant from mathematical point of view [30]. The components of space vector in $\alpha-\beta$ plane are written as a complex number.

$$
\vec{V}_{\alpha}+j \vec{V}_{\beta}=V_{\text {batt }} \frac{2}{3}\left(\vec{V}_{a}+\bar{a} \vec{V}_{b}+\bar{a}^{2} \vec{V}_{c}\right)
$$

where $\bar{a}=\exp (j 2 \pi / 3), \bar{a}^{2}=\exp (j 4 \pi / 3)$. The coefficient $2 / 3$ is chosen to ensure the magnitude of the two-phase voltages will be equal to that of the three-phase voltages after the transformation. The space vectors are represented in vector form in (18) and their corresponding switching states are given in Table. 5. 


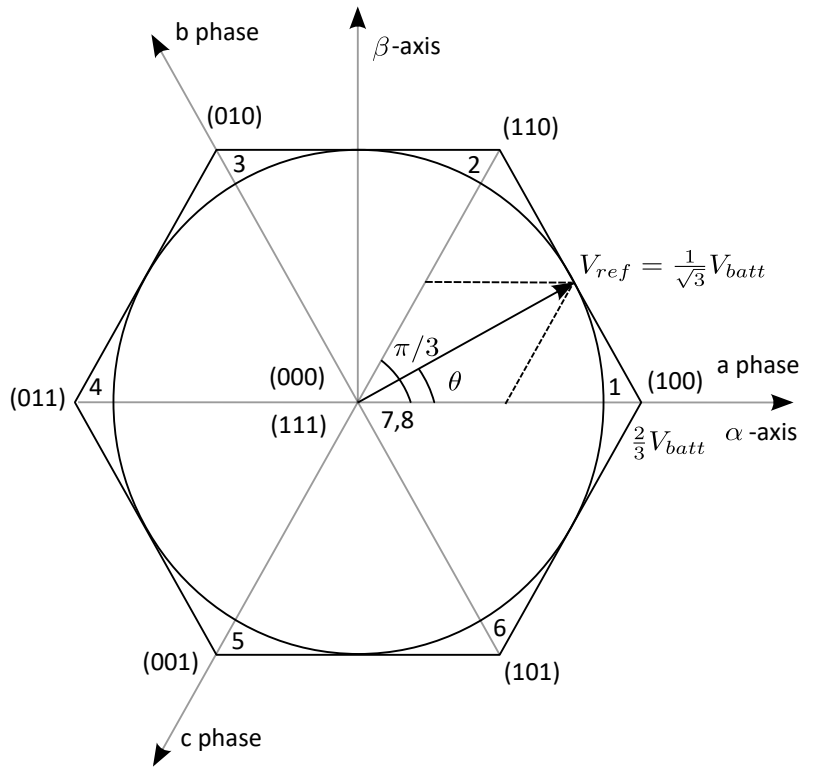

Fig. 4: Switching vectors and space vector trajectory

$$
\left[\begin{array}{l}
\vec{V}_{\alpha} \\
\vec{V}_{\beta}
\end{array}\right]=\frac{2}{3}\left[\begin{array}{ccc}
1 & \frac{-1}{2} & \frac{-1}{2} \\
0 & \frac{\sqrt{3}}{2} & \frac{\sqrt{3}}{2}
\end{array}\right]\left[\begin{array}{l}
\vec{V}_{a n} \\
\vec{V}_{b n} \\
\vec{V}_{c n}
\end{array}\right]
$$

Table 5: Phase voltage space vector

\begin{tabular}{cccc}
\hline State & $\begin{array}{c}\text { Phase voltage space } \\
\text { vectors }\end{array}$ & $V_{\alpha}$ & $V_{\beta}$ \\
\hline 1 & $(2 / 3) V_{\text {batt }}$ & $(2 / 3) V_{\text {batt }}$ & 0 \\
2 & $(2 / 3) V_{\text {batt }} \exp (j \pi / 3)$ & $(1 / 3) V_{\text {batt }}$ & $(1 / 3) V_{\text {batt }}$ \\
3 & $(2 / 3) V_{\text {batt }} \exp (j 2 \pi / 3)$ & $-(1 / 3) V_{\text {batt }}$ & $(1 / 3) V_{\text {batt }}$ \\
4 & $(2 / 3) V_{\text {batt }} \exp (j \pi)$ & $-(2 / 3) V_{\text {batt }}$ & 0 \\
5 & $(2 / 3) V_{\text {batt }} \exp (j 4 \pi / 3)$ & $-(1 / 3) V_{\text {batt }}$ & $-(1 / 3) V_{\text {batt }}$ \\
6 & $(2 / 3) V_{\text {batt }} \exp (j 5 \pi / 3)$ & $(1 / 3) V_{\text {batt }}$ & $-(1 / 3) V_{\text {batt }}$ \\
7 & 0 & 0 & 0 \\
8 & 0 & 0 & 0 \\
\hline
\end{tabular}

The reference vector, $V_{\text {ref }}$ in Fig.4, rotates in the $\alpha-\beta$ plane and occupies one of six sectors as the different sets of switches are turned on or off. The magnitude of reference voltage vector is calculated from $\vec{V}_{\alpha}$ and $\vec{V}_{\beta}$.

$$
V_{r e f}=\sqrt{\vec{V}_{\alpha}^{2}+\vec{V}_{\beta}^{2}}
$$


The angular displacement between $\vec{V}_{r e f}$ and the $\alpha$-axis is obtained by integrating the electrical frequency $\omega(t)$.

$$
\theta(t)=\int_{0}^{t} \omega(t) d t+\theta_{0}
$$

The maximum of reference voltage that corresponds to the radius of the largest possible circle that can be inscribed within the hexagon, shown in Fig. 4, is defined in (21).

$$
V_{r e f, \max }=\frac{2}{3} V_{b a t t} \cos (\pi / 6)=\frac{1}{\sqrt{3}} V_{b a t t}
$$

Similarly, the maximum fundamental line-to-line rms voltage is calculated as,

$$
V_{L L, \max }=\frac{\sqrt{3} V_{\text {ref, } \max }}{\sqrt{2}}=\frac{V_{\text {batt }}}{\sqrt{2}}=0.707 V_{\text {batt }}
$$

Modulation index is the ratio of the fundamental component amplitude of the line-to-line inverter output voltage $\left(V_{L L}\right)$ to the available dc bus voltage $\left(V_{\text {batt }}\right)$. Thus,

$$
M=\frac{V_{L L}}{V_{b a t t}}=\frac{\sqrt{3} V_{r e f}}{V_{b a t t}}
$$

Thus, the maximum modulation index in the case of SVPWM is derived as 1.

$$
M_{\text {max }}=\frac{\sqrt{3} V_{\text {ref, } \text { max }}}{V_{\text {batt }}}=\frac{\sqrt{3}\left(V_{\text {batt }} / \sqrt{3}\right)}{V_{b a t t}}=1
$$

In order to estimate the losses in the inverter, the conduction losses, switching losses and off-state blocking losses are considered as in [31]. The analytical expression of the switching loss $P_{l s}$ in IGBT devices is given by

$$
P_{l s}=\frac{6}{\pi} f_{s}\left(E_{o n, I}+E_{o f f, I}+E_{o f f, D}\right) \frac{V_{b a t t}}{V_{r}} \frac{I_{L}}{I_{r}}
$$

where $f_{s}$ is the switching frequency, $V_{b a t}$ is the dc link voltage, $I_{L}$ is the peak value of the sinusoidal line current, $E_{\text {on,I }}$ and $E_{o f f, I}$ are the turn-on and turn-off energies of the IGBT, respectively, $E_{o f f, D}$ is the turn-off energy of the power diode due to reverse recovery current. The properties of IGBT and diode are defined in Table. 6.

The conduction losses depend directly on the load current $\left(I_{L}\right)$ modulation index $(M)$ and the displacement angle $(\phi)$ between the fundamental of modulation function and the load current [31]. The conduction losses in the IGBT and the diode are expressed as

$$
\begin{aligned}
P_{l c, I} & =\frac{V_{C E, 0} I_{L}}{2 \pi}\left(1+\frac{M \pi \cos \phi}{4}\right)+\frac{r_{C E, 0} I_{L}^{2}}{2 \pi}\left(\frac{\pi}{4}+\frac{2 M \cos \phi}{3}\right) \\
P_{l c, D} & =\frac{V_{F, 0} I_{L}}{2 \pi}\left(1-\frac{M \pi \cos \phi}{4}\right)+\frac{r_{F, 0} I_{L}^{2}}{2 \pi}\left(\frac{\pi}{4}-\frac{2 M \cos \phi}{3}\right)
\end{aligned}
$$

The total inverter losses are summed over the driving to calculate the energy consumption in power electronics $\left(E_{P E}\right)$.

In the optimization routine, when the reference motor geometry is scaled down, the current rating of the machine should be increased accordingly to achieve the required output torque. The armature losses, magnet losses, and inverter losses increase with the current rating of the machine. On the other hand, the core losses decrease when the machine size is reduced. Since the NEDC is less demanding, the share of core loses is significant in the total losses. Hence, a careful evaluation of motor candidates should be made in the optimization to achieve minimum overall energy consumption of the vehicle. 


\begin{tabular}{clclc}
\hline State & Parameters & Values & Parameters & Values \\
\hline IGBT & $I_{\text {ref }}, A$ & 400 & $E_{o f f, m J}, A$ & 7 \\
& $V_{r e f}, V$ & 300 & $V_{C E, 0}, V$ & 1.6 \\
& $E_{\text {on }, m J}, A$ & 13 & & \\
\hline Diode & $r_{C E, 0}, m \Omega$ & 3.8 & $V_{F, 0}, V$ & 1.55 \\
& $r_{F, 0}, m \Omega$ & 3.9 & $E_{o f f, D}, m J$ & 7 \\
\hline
\end{tabular}

\subsubsection{Gradeability limit}

The gradability (GR) limit is defined as the grade $(\theta)$ at which the vehicle can start and climb for $20 \mathrm{~s}$ [32]. On a flat road, it can represent the available tractive force at the given speed $(v)$ for further acceleration. As the GR is more demanding due to higher duration (up to $20 \mathrm{sec}$ ) of the peak torque $T_{\text {peak }}$ and thus the current requirement, it is preferred to quantify the driving performance of the vehicle over acceleration.

$$
\begin{aligned}
G R & =\sin (\theta)=\frac{d-C_{r}^{2} \sqrt{1-d^{2}+C_{r}^{2}}}{1+C_{r}^{2}} \\
d & =\left(\frac{T_{\text {peak }} \omega_{B}}{v}-\frac{1}{2} C_{d} \rho_{0} A v^{2}\right) \frac{1}{m_{v} g}
\end{aligned}
$$

This objective function is converted into a constraint. The gradability limit requirement is translated as an inequality constraint $\Delta T_{w} \leq 60$ where $\Delta T_{w}$ is the winding temperature. This constraint enables the optimization algorithm to consider only the motor candidates that can climb the targeted grade for 20s without violating the constraint on winding temperature. A thermal model based on lumped parameter thermal networks using the distributed loss and capacitance (DLC) element described in [33] is used here to estimate the winding temperature.

\subsection{Subsystem model: Battery}

In the battery model, the cells are arranged in a balanced scheme as shown Fig. 5 to enable uniform utilization of the cells. The number of cells in series $\left(N_{s c}\right)$ and parallel $\left(N_{p c}\right)$ are taken as the design variables, and they are optimised for the consistency constraints on the linking variable battery size $\left(N_{b c}\right)$. The battery output power $\left(P_{b a t t}\right)$ is considered as the shared variables. The bounds of $N_{s c}$ and $N_{p c}$ are defined in such a way that the maximum voltage and current ratings of the battery are restricted.

Table 7: Optimization problem for the battery model

\begin{tabular}{cc}
\hline Design variables & $N_{s c}, N_{p c}$ \\
Linking variables & $N_{b c}$ \\
Shared variable & $P_{b a t t}$ \\
Constraints & $N_{E M} P_{\text {in }} \leq P_{b a t t}, E_{c} \leq E_{\text {batt }}$ \\
\hline
\end{tabular}

The battery size estimated by the battery model in (28) should be greater than or equal to the value of target linking variable from the system model.

$$
N_{b c}=N_{s c} N_{p c}
$$

The expressions of battery voltage, current, power, and available energy are given in (29). The maximum discharge pulse current rate of the $\mathrm{Li}$-ion cell is taken as $3 \mathrm{C}$, where $\mathrm{C}$ is the capacity of the cell in $\mathrm{Ah}$. The available energy in the 


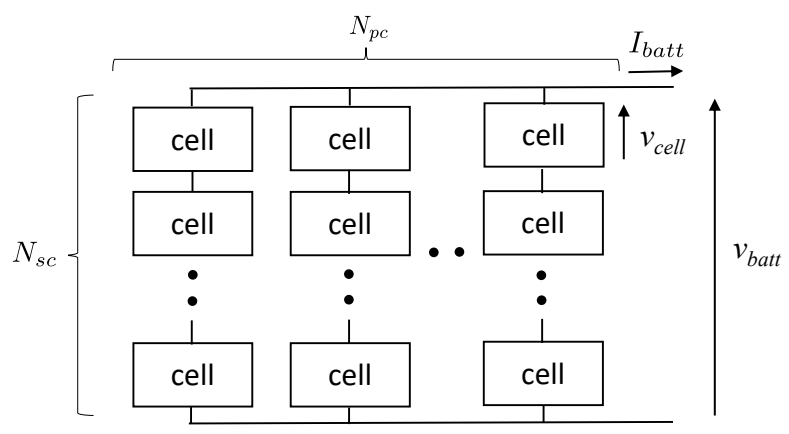

Fig. 5: Arrangement of battery cells

battery $E_{\text {batt }}$ is estimated considering $70 \% \mathrm{C}$ as the useful capacity in each cell.

$$
\begin{aligned}
V_{b a t t} & =N_{s c} V_{\text {cell }} \\
I_{b a t t} & =N_{p c} 3 C \\
P_{b a t t} & =V_{\text {batt }} I_{\text {batt }} \\
E_{\text {batt }} & =0.7 N_{s c} N_{p c} C
\end{aligned}
$$

\subsection{Subsystem model: Suspension}

A simplified quarter-car model, shown in Fig. 6, is used for describing the vertical motion of the suspension system due to the road irregularity. The model contains unsprung mass $\left(m_{1}\right)$, sprung mass $\left(m_{2}\right)$, tire stiffness $\left(k_{1}\right)$, spring stiffness $\left(k_{2}\right)$, and damper $\left(r_{2}\right)$. The variables $x_{1}$ and $x_{2}$ represent the vertical motions of the masses $m_{1}$ and $m_{2}$ respectively. The road irregularity $(r)$ is modelled as a single slope power spectral density [34,35]. In the suspension model, the objective functions

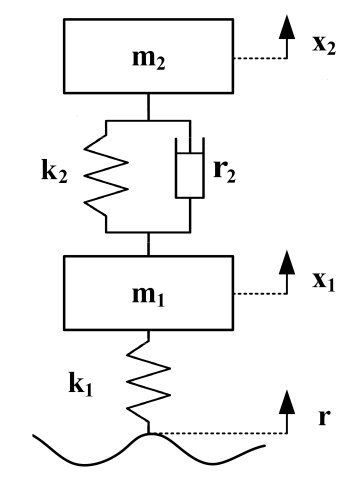

Fig. 6: Quarter car model.

Table 8: Optimization problem for the suspension model

\begin{tabular}{cc}
\hline Objective functions & $\sigma_{\ddot{x_{2}}}, \sigma_{x_{2}-x_{1}}, \sigma_{F_{z}}$ \\
Design variables & $k_{2}, r_{2}$ \\
Linking variables & $M_{s}, M_{u}$ \\
Constraints & $\sigma_{\ddot{x_{2}}} \leq c_{1} ; \sigma_{x_{2}-x_{1}} \leq c_{2} ; \sigma_{F_{z}} \leq c_{3}$ \\
\hline
\end{tabular}

are discomfort $\left(\sigma_{\ddot{x} \ddot{2}}\right)$, road holding $\left(\sigma_{F z}\right)$, and working space $\left(\sigma_{x_{2}-x_{1}}\right)$. The variables spring stiffness $\left(k_{2}\right)$ and damping ratio $\left(r_{2}\right)$ are optimized, where the remaining variables are fixed as given in Table 9. The constraints are user defined limiting values for the objective functions based on the vehicle characteristics. The sprung and unsprung masses of the quarter-car 
model are considered as the linking variables in the ATC formulation, as they get updated based on the battery size and motor dimensions.

Table 9: Data of quarter-car model, velocity, and road roughness

\begin{tabular}{ccc}
\hline Parameter & Unit & Value \\
\hline$k_{1}$ & $\mathrm{~N} / \mathrm{m}$ & 120000 \\
$v$ & $\mathrm{~m} / \mathrm{s}$ & 20 \\
$A_{b}$ & $\mathrm{~m}$ & $1.4 \mathrm{e}-5$ \\
\hline
\end{tabular}

The analytical expression of the discomfort, which is derived as the standard deviation of vertical acceleration $\left(\ddot{x_{2}}\right)$ of $m_{2}$, is given as [34].

$$
\sigma_{\ddot{x_{2}}}=\sqrt{\frac{A_{b} v}{2 m_{2}^{2}}\left(\frac{\left(m_{1}+m_{2}\right) k_{2}^{2}}{r_{2}}+k_{1} r_{2}\right)}
$$

where $A_{b}$ accounts for the road profile and $v$ is the vehicle velocity. Similarly, the analytical expression for the working space $\left(\sigma_{x_{2}-x_{1}}\right)$ is given as the standard deviation of the relative motion of $m_{2}$ with respect to $m_{1}$ [34].

$$
\sigma_{x_{2}-x_{1}}=\sqrt{\frac{A_{b} v}{2}\left(\frac{\left(m_{1}+m_{2}\right)}{r_{2}}\right)}
$$

The standard deviation of the force between tire and the ground defines the road holding $\left(\sigma_{F_{z}}\right)$ [34].

$$
\sigma_{F_{z}}=\sqrt{\frac{A_{b} v}{2}\left(m_{1}+m_{2}\right)^{2} P}
$$

where

$$
P=\left(\frac{\left(m_{1}+m_{2}\right) k_{2}^{2}}{m_{2}^{2} r_{2}}+\frac{2 k_{1} k_{2} m_{1}}{m_{2} r_{2}\left(m_{1}+m_{2}\right)}+\frac{k_{1}^{2} m_{1}}{r_{2}\left(m_{1}+m_{2}\right)^{2}}+\frac{k_{1} r_{2}}{m_{2}^{2}}\right)
$$

Weighted sum scalarization method, where the normalized objective functions are added together after multiplying with the weights $(\lambda)$ as in (34), is used for solving the MOO problem. As the problem is convex, proper optimal solutions can be found. The weights are varied based on the desired characteristics of the vehicle, for example a sport car can have more weight for road holding than discomfort.

$$
\min _{x} \quad \lambda_{1} \sigma_{\ddot{x_{2}}}+\lambda_{2} \sigma_{F z}+\lambda_{3} \sigma_{x_{2}-x_{1}}
$$

where

$$
0 \leq \lambda_{i} \leq 1 ; \quad \sum_{i=1}^{n_{o f}} \lambda_{i}=1
$$

\section{Subsystem optimization}

In the vehicle model, the $N_{b c}$ is an integer valued design variable, and the calculations of $E_{c}$ and $\Delta T_{w}$ are computationally expensive. Hence, an optimization algorithm that can handle integer design variables and requires a minimum number of functional evaluations for the convergence is suitable. Genetic algorithm and a modified simplex algorithm (MSA) are 
considered as potential candidates. In the MSA, similar to the conventional simplex method, $(\mathrm{n}+1)$ points are selected in the simplex of an n design variable problem as shown in Fig.7 and ranked based on the values of the objective function calculated at each point. After performing reflection, expansion, and contraction operations on the design candidates, the position of the new point $(R)$ is updated to the closest integer value $\left(R^{\prime}\right)$ of the required design variable. Figure 8 compares the convergence performance of the MSA and GA in terms of the final value and the required number of functional evaluations. Though the GA works reasonably well for this problem, it is observed to be slower than the MSA. Hence, the MSA is chosen as the appropriate method to solve the system level optimization problem.

The MATLAB implementation of fminsearch employs the conventional simplex method, which is an unbounded and unconstrained optimization algorithm. In order to include the bounds, the design variables are updated as per the expression given in (35) [36] in each iteration of fminsearch. Then the required design variables are updated to the closest integer value using round function in MATLAB.

$$
\begin{aligned}
x & =L B+(U B-L B) *(\sin (z)+1) / 2 \\
x(*) & =\operatorname{round}(x(*))
\end{aligned}
$$

where LB and UB correspond to the lower bounds and upper bounds of the design variables, $\mathrm{z}$ is the fully unconstrained design variables vector, and $\mathrm{x}$ is the design variables vector within the bounds. The symbol $*$ denotes the position of the integer-valued design variable. The inequality constraints $(g)$ are converted into penalty functions (exterior) as in (37) and added to the objective function $\left(E_{c}\right)$. Thus, the problem is transformed into an unconstrained optimization problem, which can be solved using fminsearch.

$$
P F=\frac{1}{2} \sum_{i=1}^{m}(\max 0, g)^{2}
$$

In the battery model, both the $N_{s c}$ and $N_{p c}$ are integer valued design variables. Especially, the $N_{p c}$ has only a few design possibilities within the bounds, so the MSA does not work well as it gets locked in the initial values of $N_{p c}$. The genetic algorithm can be a good alternative as the battery model is computationally simple. A population size of 100 with 20 generations has given consistent results for the optimum layout of battery cells. The standard stochastic transition rules such as mutation and crossover are employed for getting the genetically improved populations in the successive generations. The individual with maximum fitness value at the final generation is considered to be the optimum solution. On the other hand, the objective functions and constraints in the suspension model are continuously differentiable with respect to the continuous design variables, so the MATLAB implementation of sequential quadratic programming ( fmincon) is utilized effectively for the accurate and computationally efficient results.

\section{Hierarchical multi-objective optimization}

Optimising the subsystems separately and combining them together does not give the overall optimum solution. The synergistic solution can be achieved only when the interactions between the subsystems are maintained. The ATC algorithm manages the interactions using consistency constraints of the linking variables $\left(t_{i j}=r_{(i+1) j}\right)$. It is important to relax these

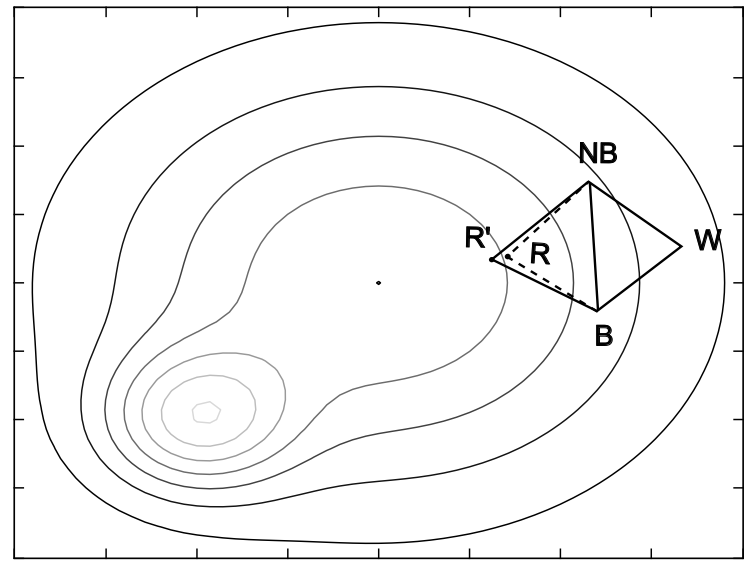

Fig. 7: Modified simplex algorithm. 


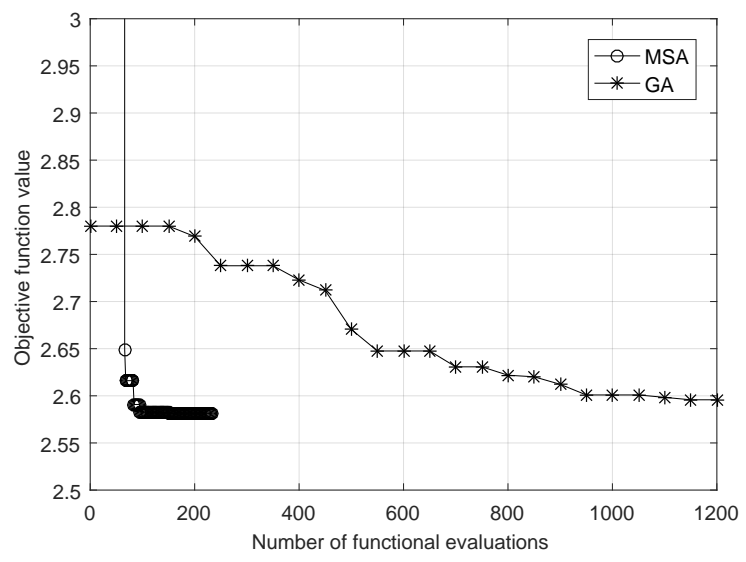

Fig. 8: Comparison of convergence performance of modified simplex algorithm (MSA) and genetic algorithm (GA).

consistency constraints in order to ensure convergence of the problem [22]. Augmented-Lagrangian penalty function $(\phi)$ is used on the difference of linking variables as defined in (1).

The number of battery cells $\left(N_{b c}\right)$ required from the vehicle model is cascaded down to the battery model as a target. Similarly, the sprung mass $\left(m_{1}\right)$ and unsprung mass $\left(m_{2}\right)$ of the vehicle which are calculated from the optimised design variables $k_{a}, k_{r}$, and $N_{b c}$ as in (38) are passed to the suspension model.

$$
\begin{array}{r}
m_{1}=k_{r}^{2} k_{a} m_{m o t o r, \text { ref }}+m_{\text {fixed }} \\
m_{2}=\left(m_{\text {body }}+N_{b s} m_{\text {cell }} k_{p c}\right) / 4
\end{array}
$$

where $m_{\text {motor, ref }}$ is the mass of the reference motor, $m_{\text {fixed }}$ is the mass of wheel end that is not influenced by scaling, $m_{b o d y}$ is the vehicle body mass, and $m_{\text {cell }}$ is the battery cell mass. The battery pack to cell weight ratio $\left(k_{p c}\right)$ is obtained through bench-marking the existing vehicle data and its value for Li-ion battery is $\approx 1.8$. The shared variable $P_{i n}$ is formulated using the rated voltage $\left(V_{r}\right)$ and the maximum current $\left(I_{\max }\right)$ of the motor.

$$
P_{\text {in }}=\sqrt{3} V_{r} I_{\text {max }}
$$

The subsystem level models verify if the targets from system model can be achieved without violating the local constraints. When the targets are not met, feedback is sent back by updating the linking variables, and the vehicle model is optimised again. When the consistency deviation between the target and response linking variables is within a predefined variable, the optimization process is completed as presented in Table. 10. The hierarchical flowchart of the in-wheel motor electric vehicle model is given in Fig.9.

Table 10: Evolution of consistency deviation considering gradeability limit of 30\%. Stopping criteria: $\varepsilon_{1}=\varepsilon_{2}=0.01$

\begin{tabular}{ccc}
\hline Iteration & $\left\|c_{s}^{n}\right\|$ & $\left\|c_{s}^{n}-c_{s}^{n-1}\right\|$ \\
\hline 1 & $\inf$ & 0.3873 \\
2 & 0.3653 & 0.0253 \\
3 & 0.0244 & 0.0031 \\
4 & 0.0066 & 0.0058 \\
\hline
\end{tabular}

In the proposed hierarchical multi-objective optimization model, Pareto-optimal front between the objective functions in the vehicle model is generated using the constraint method (39) $[8,37]$.

$$
\begin{gathered}
\min _{x \in \mathcal{F}} E_{c}+\phi_{11} \\
E_{c} \leq E_{\text {batt }} \quad N_{E M} P_{\text {in }} \leq P_{\text {batt }} \quad \Delta T \leq 60 \quad S P L \leq 15
\end{gathered}
$$




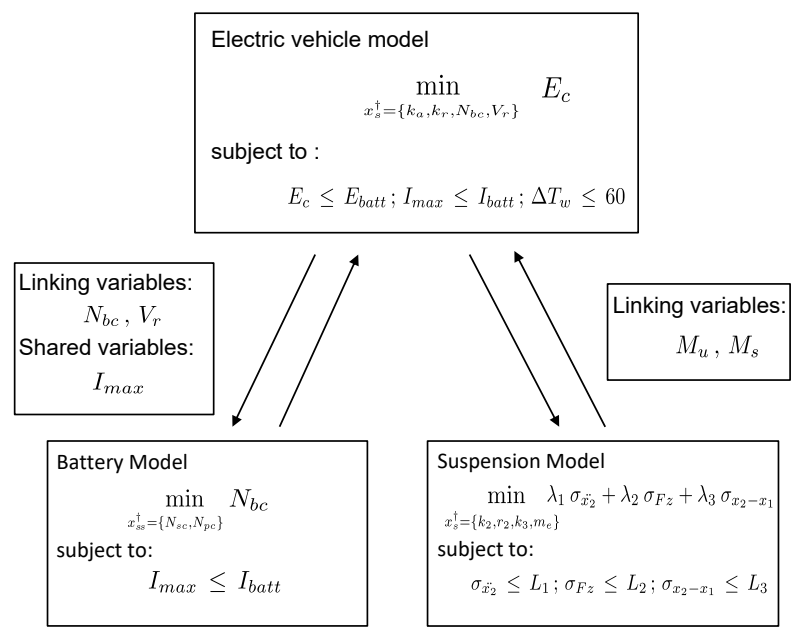

Fig. 9: Hierarchical partitioning structure for in-wheel motor electric vehicle.

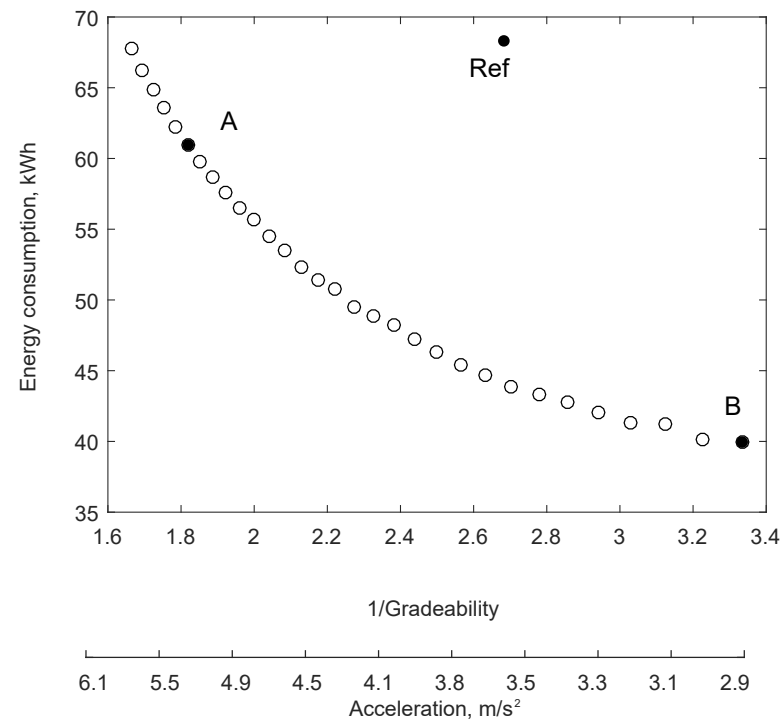

Fig. 10: Pareto-optimal set between energy consumption and the inverse of gradeability limit.

The results are plotted in Fig.10 between energy consumption and the inverse of gradability limit (GL), which converts GL to a minimization function. Equivalent acceleration is also shown in the second x-axis. Similarly, the Pareto-optimal front of the suspension system, which is obtained by varying the weights $\left(\lambda_{i}\right)$ in (34), is given between discomfort, road holding, and working space in Fig. 11 for specific values of $m_{1}$ and $m_{2}$. Optimum values of design variables that correspond to two example vehicles, namely A and B as shown in the figures, are presented in Table. 11 along with the reference vehicle parameters. The vehicle A has the gradability limit of 55\% and high weight for the discomfort. On the other hand, the vehicle B has 30\% GL and high weight for the road holding. Thus the analytical target cascading together with MOO techniques can be used effectively to optimise the in-wheel motor electric vehicle.

\section{Comparison with All-in-one optimization}

The performance of proposed ATC based methodology is compared with the All-in-one (AiO) or single level optimization model in terms of its accuracy and calculation time. Two different AiO models are considered in this study. In the first model, the vehicle mass is fixed at the beginning of optimization. In other words, the vehicle mass does not change with motor and battery sizes (the design variables). In the second model, the motor and battery sizes are used to estimate the vehicle mass while considering fixed values for the body and front axle masses. In order to generalize the models between the different approaches, a simplified multi-level optimization model is built considering only the vehicle and battery models 


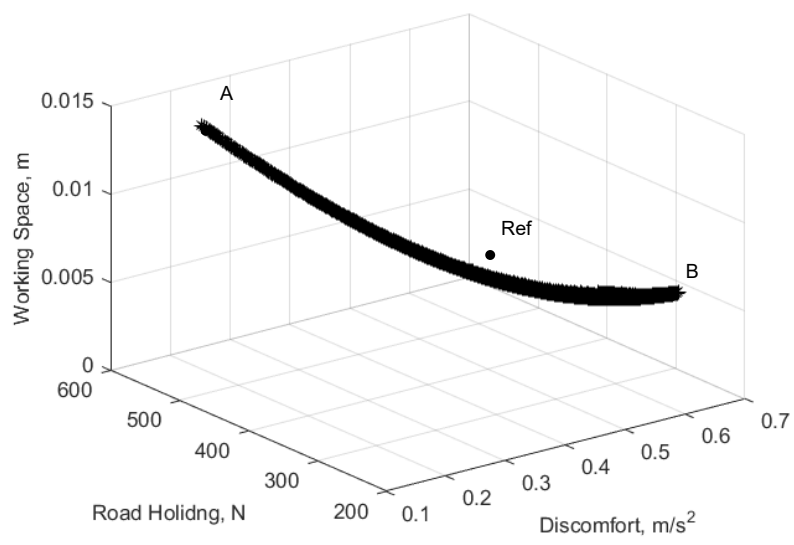

Fig. 11: Pareto-optimal set of the suspension architecture S5 in the objective functions domain where $m_{2}=310 \mathrm{~kg}$ and $m_{1}=45 \mathrm{~kg}$.

Table 11: Optimum values of the design parameters for vehicles A and B

\begin{tabular}{lcccc}
\hline Parameters & Symbol & Reference & Optimum-A & Optimum-B \\
\hline Pole number & $2 p$ & 40 & 40 & 40 \\
Slot number & $Q_{s}$ & 120 & 120 & 120 \\
Magnet arc, $\%$ & $\alpha_{p}$ & 0.75 & 0.75 & 0.75 \\
Air gap length, mm & $g$ & 1.2 & 1.4 & 1.1 \\
Inner rotor radius, mm & $R_{r}$ & 144.8 & 167.2 & 129.9 \\
Inner magnet radius, mm & $R_{m}$ & 148.8 & 171.9 & 133.5 \\
Outer stator radius, mm & $R_{s}$ & 150 & 173.3 & 134.6 \\
Core length, mm & $l_{s t k}$ & 66 & 79.2 & 69.8 \\
Slot opening, mm & $b_{0}$ & 3.6 & 4.2 & 3.2 \\
Slot depth, mm & $d_{s}$ & 13 & 15.0 & 11.7 \\
Number of conductors in a slot & $N_{s}$ & 6 & 6 & 6 \\
Maximum current, A & $I_{\max }$ & 297.9 & 313.7 & 217.2 \\
Rated voltage, V & $V_{r}$ & 200 & 153 & 153 \\
Number battery cells & $N_{b c}$ & 200 & 444 & 312 \\
Suspension spring stiffness, N/m & $k_{2}$ & 10000 & 14810 & 20000 \\
Suspension damping ratio, Ns/m & $r_{2}$ & 1000 & 1230 & 1727 \\
\hline
\end{tabular}

as in Fig. 12. The suspension model and the acoustic performance evaluation, discussed in Section 5, are not included as it is difficult to manage five objective functions together in the AiO formulation.

This multi-level optimization problem is solved using the ATC approach as discussed in Section 5 and the Pareto optimal solutions between the energy consumption and inverse of gradability are given in Fig. 15.

\subsection{All-in-one model with fixed vehicle mass}

In the AiO approach, the electric vehicle and battery models are combined and optimised using a single solver. The objective functions are the energy consumption $\left(E_{C}\right)$ and the inverse of gradability. The considered design variables are the axial and radial scaling ratios, maximum current, and rated voltage of the motor. The battery size is calculated from the optimised energy consumption and the rated voltage in post processing stage. The Pareto-optimal solutions between the energy consumption and inverse of gradeability are computed using constrained method. The gradeability requirement is transformed into a constraint and the sequential quadratic programming (SQP) algorithm is used to solve the problem.

\subsection{All-in-one model considering the variations of vehicle mass}

The variations of the vehicle mass can be captured in the optimization process by modelling it as a function of motor scaling ratios and number of battery cells as given in (38). Similar to the fixed vehicle mass model, the energy consumption and inverse of gradability are taken as the objective functions. The design variables are radial and axial scaling ratios $\left(k_{a}\right.$ and 


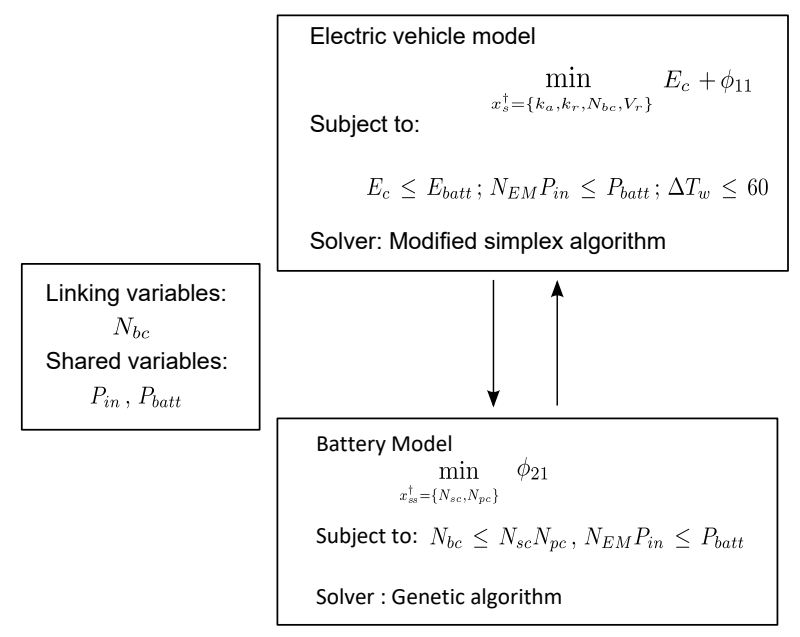

Fig. 12: A simplified two level electric vehicle model

$$
\begin{aligned}
& \text { Electric vehicle All-in one model } \\
& \qquad \min _{s}^{\dagger}=\left\{k_{a}, k_{r}, I_{\max }, V_{r}\right\} \quad E_{c} \\
& \text { Subject to: } \\
& \qquad L=\epsilon ; \Delta T \leq 60 \\
& \text { Solver: Sequential quadratic programming }
\end{aligned}
$$

Fig. 13: Problem formulation with fixed vehicle mass

$\left.k_{r}\right)$, maximum current $\left(I_{\max }\right)$, number of battery cells in series $\left(N_{s c}\right)$ and parallel $\left(N_{p c}\right)$.

As discussed in Section 4, the design variables $N_{s c}$ and $N_{p c}$ are integer valued functions which mandate the use of evolutionary algorithms to solve this non-linear optimization problem. Genetic algorithm is used to solve this mathematical programming problem.

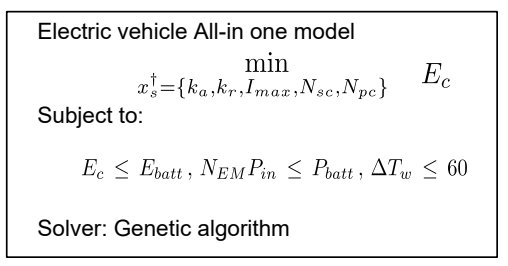

Fig. 14: All-in one problem formulation considering the variations of vehicle mass

\subsection{Comparative analysis}

The Pareto optimal sets from the proposed hierarchical method and AiO approaches are compared in Fig. 15 where the benefit of modelling the vehicle mass as a function of the motor and battery sizes is evident. When the gradability or acceleration demand is high, the motor size should be scaled up in order to achieve the required torque. This results in increased vehicle mass and energy consumption. Conversely, when the gradability or acceleration requirement is low, the actual energy consumption will be lower than the estimation of the fixed vehicle mass model.

The AiO approach with fixed vehicle mass does not capture this effect and estimates lower energy consumption as shown in Fig. 15. On the other hand, the AiO approach considering the vehicle mass variation gives similar results with respect to proposed ATC based method. However, the computational time of the evolutionary algorithms required to solve this problem is unacceptable. Table 12 compares the calculation time of all the three formulations estimated with a standard laptop (Intel i7-4700MQ CPU @ 2.4 GHz, 16GB RAM).

From the shown results, it can be suggested that the proposed ATC based optimization algorithm is quite useful in the pre-design stage of complex systems such as in-wheel motor electric vehicles in achieving accurate solutions with reasonable 


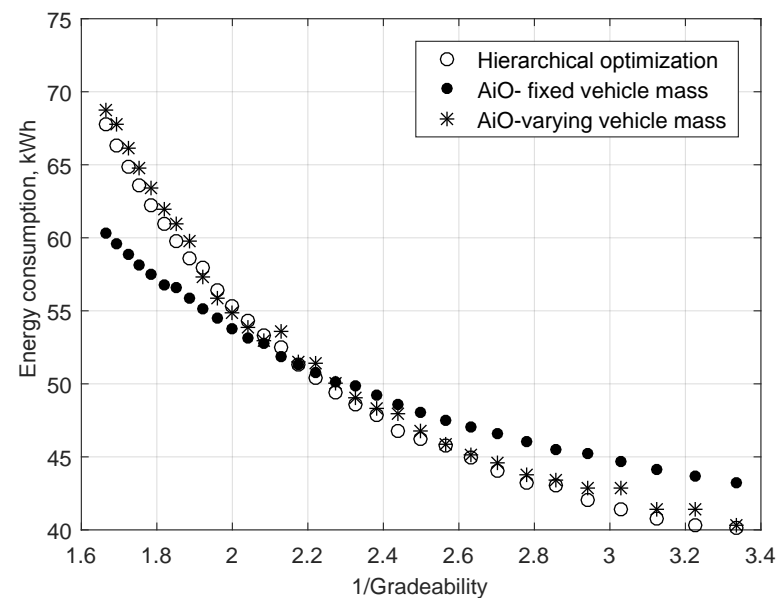

Fig. 15: Comparison of Pareto optimal sets obtained from AiO optimization models and proposed methodology

Table 12: Calculation time of the optimization methods.

\begin{tabular}{cc}
\hline optimization model & Calculation time, s \\
\hline Proposed optimization method & 440 \\
AiO with fixed vehicle mass & 111 \\
AiO with vehicle mass variation & 4601 \\
\hline
\end{tabular}

calculation time.

\section{Conclusion}

In this application-oriented paper, an in-wheel motor electric vehicle optimization problem with high dimensionality of has been solved using the analytical target cascading approach together with MOO techniques. The complex model is divided into subsystems such as vehicle, battery, and suspension, which are arranged in a hierarchical order. The linking variables (number of battery cells, sprung, and unsprung masses) and shared variables (rated power of the motor and battery power) confirm the interactions between subsystems. Multi-physics analytical models are presented for all the subsystems and used in the ATC structure. A modified simplex algorithm is proposed to solve the vehicle model with integer valued design variables, which works faster than the evolutionary algorithms. The battery and suspension models are solved using genetic algorithm and sequential quadratic programming respectively. The Pareto-optimal solution for the vehicle and suspension models are obtained by solving synergistically the complete vehicle problem. The optimum design parameters, including the electric motor geometry, for two different vehicle types are presented in detail. The comparative analysis shows that the proposed ATC based method works significantly better than the conventional AiO approach for complex design optimization problems.

\section{References}

[1] Kim, H. M., Michelena, N. F., Papalambros, P. Y., and Jiang, T., 2003. "Target cascading in optimal system design". Journal of mechanical design, 125(3), pp. 474-480.

[2] Michelena, N., Park, H., and Papalambros, P. Y., 2003. "Convergence properties of analytical target cascading”. AIAA journal, 41(5), pp. 897-905.

[3] Kianifar, M. R., and Campean, I. F., 2014. "Analytical target cascading framework for engine calibration optimisation". International Journal of Powertrains, 3(3), pp. 279-302.

[4] Li, Z., Kokkolaras, M., Papalambros, P., and Hu, S. J., 2008. "Product and process tolerance allocation in multistation compliant assembly using analytical target cascading". Journal of Mechanical Design, 130(9), p. 091701.

[5] Michalek, J. J., Feinberg, F. M., and Papalambros, P. Y., 2005. "Linking marketing and engineering product design decisions via analytical target cascading”. Journal of Product Innovation Management, 22(1), pp. 42-62.

[6] Marler, R. T., and Arora, J. S., 2010. "The weighted sum method for multi-objective optimization: new insights". Structural and multidisciplinary optimization, 41(6), pp. 853-862. 
[7] D'Errico, G., Cerri, T., and Pertusi, G., 2011. "Multi-objective optimization of internal combustion engine by means of 1d fluid-dynamic models". Applied Energy, 88(3), pp. 767-777.

[8] Mastinu, G., Gobbi, M., and Miano, C., 2007. Optimal design of complex mechanical systems: with applications to vehicle engineering. Springer Science \& Business Media.

[9] Deb, K., 2015. Multi-objective evolutionary algorithms.

[10] Ramakrishnan, K., Gobbi, M., and Mastinu, G., 2015. "Multi-objective optimization of in-wheel motor powertrain and validation using vehicle simulator". In EVER, Tenth International Conference on 2015, IEEE, pp. 1-9.

[11] Ramakrishnan, K., Yang, L., Ballo, F. M., Gobbi, M., and Mastinu, G., 2016. "Multi-objective optimization of road vehicle passive suspensions with inerter". In ASME 2016, American Society of Mechanical Engineers, pp. V003T01A007-V003T01A007.

[12] Zhang, B., Chen, Z., Mi, C., and Murphey, Y. L., 2009. "Multi-objective parameter optimization of a series hybrid electric vehicle using evolutionary algorithms". In Vehicle Power and Propulsion Conference, 2009. VPPC'09. IEEE, IEEE, pp. 921-925.

[13] Ramakrishnan, K., Curti, M., Zarko, D., Mastinu, G., Paulides, J. J., and Lomonova, E. A., 2017. "Comparative analysis of various methods for modelling surface permanent magnet machines". IET Electric Power Applications, 11(4), pp. 540-547.

[14] Zhu, Z., Howe, D., Bolte, E., and Ackermann, B., 1993. "Instantaneous magnetic field distribution in brushless permanent magnet dc motors. i. open-circuit field". IEEE Transactions on Magnetics, 29(1), pp. 124-135.

[15] Žarko, D., Ban, D., Lipo, T., et al., 2008. "Analytical solution for cogging torque in surface permanent-magnet motors using conformal mapping". IEEE Transactions on Magnetics, 44(1), pp. 52-65.

[16] Boughrara, K., Zarko, D., Ibtiouen, R., Touhami, O., and Rezzoug, A., 2009. "Magnetic field analysis of inset and surface-mounted permanent-magnet synchronous motors using schwarz-christoffel transformation". IEEE Transactions on Magnetics, 45(8), pp. 3166-3178.

[17] Gysen, B. L. J., Meessen, K. J., Paulides, J. J. H., and Lomonova, E. A., 2010. "General formulation of the electromagnetic field distribution in machines and devices using fourier analysis". IEEE Transactions on Magnetics, 46(1), Jan, pp. 39-52.

[18] Sprangers, R., Paulides, J., Gysen, B., and Lomonova, E., 2016. "Magnetic saturation in semi-analytical harmonic modeling for electric machine analysis". IEEE Transactions on Magnetics, 52(2), pp. 1-10.

[19] Zarko, D., Ban, D., Lipo, T., et al., 2006. "Analytical calculation of magnetic field distribution in the slotted air gap of a surface permanent-magnet motor using complex relative air-gap permeance". Magnetics, IEEE Transactions on, 42(7), pp. 1828-1837.

[20] Gobbi, M., Levi, F., and Mastinu, G., 2006. "Multi-objective stochastic optimisation of the suspension system of road vehicles". Journal of sound and vibration, 298(4), pp. 1055-1072.

[21] Guarneri, P., Gobbi, M., and Papalambros, P. Y., 2011. "Efficient multi-level design optimization using analytical target cascading and sequential quadratic programming”. Structural and Multidisciplinary Optimization, 44(3), pp. 351-362.

[22] Tosserams, S., Etman, L., Papalambros, P., and Rooda, J., 2006. "An augmented lagrangian relaxation for analytical target cascading using the alternating direction method of multipliers". Structural and multidisciplinary optimization, 31(3), pp. 176-189.

[23] Mastinu, G., and Ploechl, M., 2014. Road and Off-Road Vehicle System Dynamics Handbook. CRC Press.

[24] Ramakrishnan, K., Romanazzi, P., Zarko, D., Mastinu, G., Howey, D. A., and Miotto, A., 2017. "Improved analytical model of an outer rotor surface permanent magnet machine for efficiency calculation with thermal effect". SAE International Journal of Alternative Powertrains, 6(2017-01-0185), pp. 34-46.

[25] Stipetic, S., Zarko, D., and Popescu, M., 2016. "Ultra-fast axial and radial scaling of synchronous permanent magnet machines". IET Electric Power Applications, 10(7), pp. 658-666.

[26] Žarko, D., 2004. "A systematic approach to optimized design of permanent magnet motors with reduced torque pulsations". PhD thesis, Department of Electrical and Computer Engineering, University of Wisconsin-Madison.

[27] Gieras, J., 2011. Permanent Magnet Motor Technology: Design and Applications, Third Edition. Electrical and Computer Engineering. CRC Press.

[28] De Doncker, R., Pulle, D. W., and Veltman, A., 2010. Advanced electrical drives: analysis, modeling, control. Springer Science \& Business Media.

[29] Iqbal, A., Ahmed, S. M., Khan, M. A., and Abu-Rub, H., 2010. "Generalised simulation and experimental implementation of space vector pwm technique of a three-phase voltage source inverter". International Journal of Engineering, Science and Technology, 2(1), pp. 1-12.

[30] Wu, B., and Narimani, M., 2017. High-power converters and AC drives. John Wiley \& Sons.

[31] Hassan, W., and Wang, B., 2012. "Efficiency optimization of pmsm based drive system". In Power Electronics and Motion Control Conference (IPEMC), 2012 7th International, Vol. 2, IEEE, pp. 1027-1033.

[32] Administration, F., 1996. "The code of federal regulations of the united states of america". p. 10 CRF 420.1.

[33] Romanazzi, P., Galizzi, V., Carbone, F., Miotto, A., and Howey, D., 2016. "Improved thermal equivalent circuit element 
applied to an external rotor spm machine”. In ICEM, 2016 XXII International Conference on, IEEE, pp. $2718-2724$.

[34] Gobbi, M., and Mastinu, G., 2001. "Analytical description and optimization of the dynamic behaviour of passively suspended road vehicles". Journal of sound and vibration, 245(3), pp. 457-481.

[35] Scheibe, F., and Smith, M. C., 2009. "Analytical solutions for optimal ride comfort and tyre grip for passive vehicle suspensions". Vehicle System Dynamics, 47(10), pp. 1229-1252.

[36] D’Errico, J., 2005. Bound constrained optimization using fminsearch: fminsearchbnd. matlab® central.

[37] Miettinen, K., 2012. Nonlinear multiobjective optimization, Vol. 12. Springer Science \& Business Media. 